\title{
Modeling Catchbasins and Inlets in SWMM
}

\section{Matthew Senior, Ron Scheckenberger and Brian Bishop}

Amec Foster Wheeler Environment \& Infrastructure, Burlington, Ontario.

\begin{abstract}
Early hydrologic and hydraulic numerical modeling of urban drainage systems focused on the minor system (i.e. storm sewer only). Over the past three decades there has been increased interest in the concurrent evaluation of the conveyance capacity of the major system (i.e. overland flow-roadways). More and more, these two systems are being modeled dynamically, using a linked approach known as dual drainage modeling. Dual drainage modeling allows for an improved assessment of the deficiencies in both systems, through integrated assessments which consider the interaction between the two systems.

Of key interest in dual drainage models is the representation of inlet capture functions (roadway catchbasins and ditch inlets) since these intrinsically link the two often-parallel flow conveyance systems. The accurate representation of these features is critical, given the potential implications for basement flooding, surface ponding or flooding, and the development of appropriate drainage system designs.

This paper describes various methods of modeling these functions and assesses them under different conditions, using models that had been developed for several urban communities. The relative benefits and drawbacks of each method are given and discussed, along with associated considerations for minor and major system design in dual drainage modeling.
\end{abstract}

\section{Introduction}

\subsection{Modeling Approaches for Urban Drainage Systems}

Urban areas, when compared to undeveloped rural areas, are characterized by increased development densities, roadways, and increases in impervious surfaces. Specific drainage systems are developed to service these areas, which have higher peak flows and more rapid hydrologic responses than undeveloped rural areas. Given the extent of impervious surfaces and the higher value of space (land) in urban areas, urban drainage conveyance systems have typically been human-created engineered solutions, particularly subsurface storm sewers.

Engineering designs for storm sewers have commonly been based on the assumption of full capture; that is, that all runoff for a design event (a 1 in $n$ year storm; typically the $2 \mathrm{y}$, 5 y or 10 y storm event in Ontario) would be fully captured and conveyed by the storm sewer system. Many urban drainage system designs do not consider anything beyond the storm sewer design. Some designs may also consider the major system (overland flow), but typically apply a simplified approach (i.e. the assumptions that all flows above the $n$ y storm event become major flows, and that the minor system flows remain unchanged for storms greater than the $n$ y storm event).
In reality, the urban drainage system is considerably more complex. Surface runoff in urban areas must first be collected by surface inlets (catchbasins and ditch inlets) and then directed to the storm sewer system (see Figure 1).

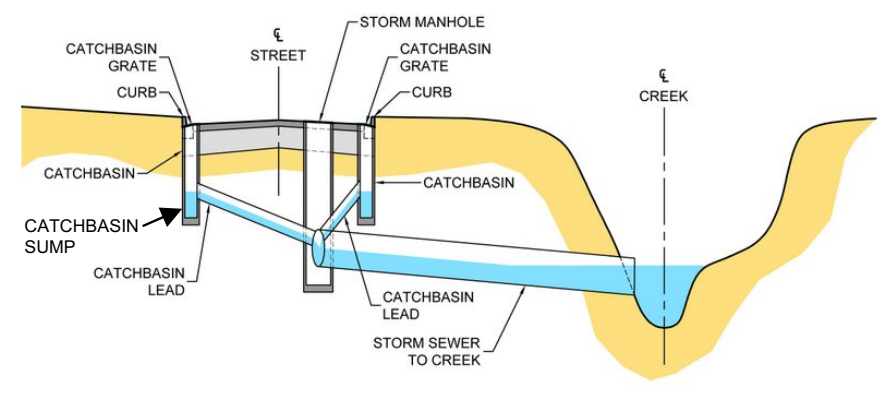

Figure 1 Typical storm sewer system.

These inlets have a limited capacity for inflow, such that not all flow directed towards a catchbasin will necessarily enter the storm sewer system at that location, particularly for catchbasins on steeper slopes, where splashover of the catchbasin grate is more common. As an example, design curves indicate that for a roadway with a $2 \%$ cross-fall and a $2 \%$ longitudinal slope, the gutter-roadway flow is $0.2 \mathrm{~m}^{3} / \mathrm{s}$ at a roadway spread

Senior, Matthew, Ron Scheckenberger and Brian Bishop. 2018. Modeling Catchbasins and Inlets in SWMM.

Journal of Water Management Modeling 26:C435. https://doi.org/10.14796/JWMM.C435 @ CHI 2018. www.chijournal.org ISSN 2292-6062. 
of $3 \mathrm{~m}$ (MTO 1997). The capture of a single catchbasin with these same parameters is estimated at $0.06 \mathrm{~m}^{3} / \mathrm{s}$, or $30 \%$ of full flow. Others (Despotovic 2005) have noted that inlet efficiency (flow capture divided by approach flow) is generally limited for a number of reasons (grate position, grading, clogging, or debris) and that excess flow will simply pass over the grate, and accumulate on the roadway.

The catchbasin lead (the connection between the catchbasin sump and the storm sewer) may also have hydraulic capacity limitations, depending on the slope and size selected. For larger storm events, the hydraulic capture performance of catchbasins may be even less certain, with further instances of bypass and the accumulation of major system (surface) flows. In some cases, particularly at roadway sag points, the converse may be true: greater inflows via catchbasins lead to storm sewer surcharge and potentially flooding. This may be particularly problematic in areas where residences have foundation drains directly connected to the storm sewer system.

It should be noted that for roadways, various municipal standards and guidelines tend to mandate catchbasin spacing based on roadway classification and profile grade. While it is generally assumed that these spacing requirements take catchbasin inlet capacity into account, there is typically no clear explanation concerning the source of these spacing and geometry standards or of the rationale for variations between municipalities, other than local preferences or experience. Typical roadway designs do not explicitly calculate or verify inlet capacity; rather it is generally assumed that adherence to municipal standards for catchbasin spacing will address performance requirements.

Both laboratory and theoretical analyses of catchbasin inlet capacity have been undertaken by various groups in Canada, primarily in the 1980s, although some work was done earlier (Black 1967). Of particular relevance in Ontario is the work of Marsalek (1982). The laboratory testing conducted as part of that work forms the basis for the design charts provided in the Ontario Ministry of Transportation's Drainage Management Manual (MTO 1989; 1997). These charts provide ranges in expected grate inflow capacity based on different catchbasin grate and roadway curb types, roadway cross-falls, and profile grades. No charts are provided for curb or side inlet catchbasins. There is limited information about which previous studies have considered the impact of the catchbasin lead size rather than the grate, as well as the potential impacts of flow restrictors and inlet control devices (ICDs) on the catchbasin lead. Given the age of many of these studies, reports or design charts are not readily available.

In conjunction with the increased interest in catchbasin inlet capacity in the 1980s, advances in computational capacity and the complexity of hydrologic and hydraulic engineering software led to an increased interest in dual drainage modeling. Numerous software programs have been developed which can undertake this analysis, including the U.S. Environmental Protection Agency's SWMM (EPA-SWMM). Researchers with a specific interest in the minor-major system interaction have analysed inlets using less commonly used modeling platforms (Bazin et al. 2014, Palla et al. 2016).

Dual drainage modeling allows for a concurrent evaluation of the conveyance capacity of both the minor system (the storm sewer) and the major system (overland flow-roadways). Dual drainage modeling allows for an improved assessment and understanding of potential deficiencies in both systems, through integrated assessments which consider the hydraulic interaction between the two systems. Of key interest in dual drainage models is the representation of inlet capture functions (catchbasins and ditch inlets), since these intrinsically link the two often parallel flow conveyance systems. Understanding the differences in methods of modeling inlet capture functions (in SWMM in particular) is therefore fundamental to the generation of an effective dual drainage model, and thus to a better understanding of urban drainage system performance and the design of better urban drainage features.

\subsection{Problem Statement and Methodology}

This paper assesses and quantifies the differences in modeling methodologies for catchbasins and inlets. Accurate representation of these features is critical, given the potential implications for basement flooding, surface ponding or flooding, to the development of an appropriate drainage system design. By better understanding these differences, and identifying the most appropriate modeling methodologies, dual drainage models can be created and used more effectively, and the most appropriate drainage system design selected for implementation.

For this assessment, PCSWMM (as a pre-processor and decision support system for EPA-SWMM) was utilised. In order to represent a variety of physical conditions, three different dual drainage modeling projects have been used as the basis for the assessment. It should be understood that these projects are used as examples only; the results presented herein are for comparison purposes and do not necessarily reflect the results of the original studies and reports.

In addition to the simulation of the original catchbasin modeling methodology for each of the project examples, alternative approaches have also been assessed for comparison purposes. The methods that were assessed are outlined below. Methods 3, 4 and 5 attempt to explicitly account for issues around inlet capacity, as well as efficiency. Note that inlet efficiency issues due to debris clogging have not been included in the current analysis.

\section{Method 1: No Inlet Capacity Restriction}

In this method, it is assumed that there is no inlet capacity restriction between the minor (storm sewer) and major (overland flow) systems. Inlet points are assumed to be oversized such that all major flows can enter the minor system at that point, and any surcharge from the minor system can be directed to the major system without restriction. This scenario has been modeled using two different approaches. In method 1A (refer to Figure 2), both 
the minor system and the major system are connected to the same upstream and downstream nodes, such that these systems are directly connected without any restriction (i.e. surface flow would drain to the lower storm sewer system first, and surcharge would discharge freely to the surface at the roadway elevation). In method 1B (refer to Figure 3), all catchbasins are represented as orifices (representing the catchbasin grate) with an oversized dimension of $4 \mathrm{~m} \times 4 \mathrm{~m}$ at each inlet point (i.e. as wide as a typical roadway lane). The use of orifices allows for the movement of flow in both directions. Although both methods can be applied relatively simply, they do not properly account for the actual inlet restriction of catchbasins, and would therefore likely overestimate inflows to the storm sewer system (and underestimate flows for the major, roadway, system).

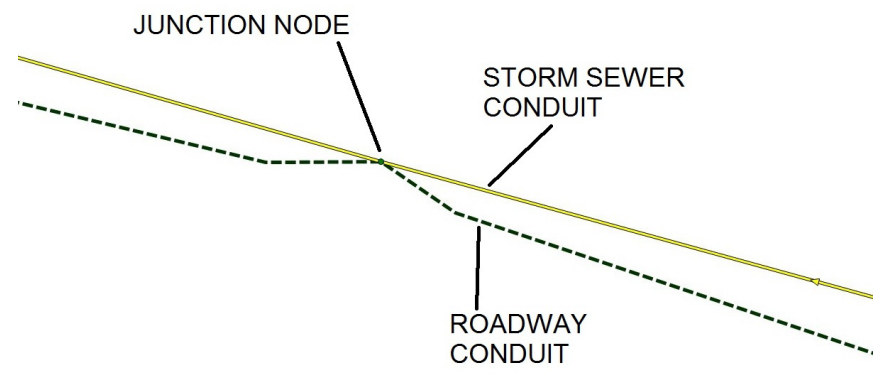

Figure 2 Inlet modeling method 1A (minor and major systems connected).

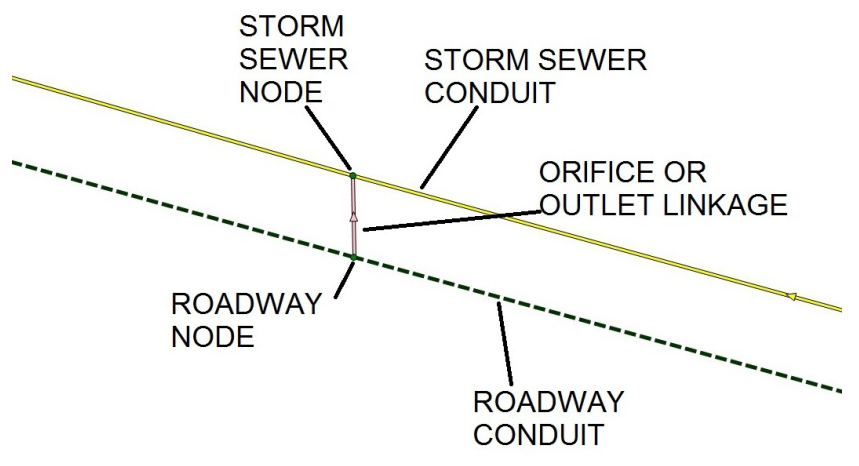

Figure 3 General linkage of minor and major systems (single orifice or rating curve).

\section{Method 2: Absolute Flow Restriction}

In this method, inlet capacity is assumed to be equal to the design flow for the minor system, typically the $2 \mathrm{y}, 5 \mathrm{y}$ or $10 \mathrm{y}$ storm event. Thus any flow in excess of this storm event is assumed to be entirely conveyed by the major system. In this method the minor system model is run first for the design event, without any inlet capacity restriction. Peak flows at all points of interest are noted. A major-system-only model is then constructed, without any connection to the minor system. The previously simulated storm sewer design flows are deducted from the simulated flows for storm events in excess of the design event to determine the net major flows. Similar to method 1, this method can be applied relatively simply, however it would be expected to underestimate inflows to the storm sewer system for more formative storm events, and correspondingly overestimate major system flows.

\section{Method 3: Simplified Rating Curve}

In this method, outlets (features in stormwater management, SWM) are used to link the major and minor systems. The general layout will be consistent with that shown in Figure 3. Outlet functionality is defined by a head-outflow rating curve, set relative to the grate (gutter) elevation. A simplified rating curve for each catchbasin is used, whereby full inlet capacity is reached at a nominal depth of $0.03 \mathrm{~m}$ (largely consistent with James et al. 2009, although a lesser depth of $0.003 \mathrm{~m}$ is used in that case). Modeling is generally sensitive to this starting depth; this is discussed further in section 2.5. Each catchbasin has an assumed inlet capacity of $50 \mathrm{~L} / \mathrm{s}\left(0.05 \mathrm{~m}^{3} / \mathrm{s}\right)$, which is also generally consistent with inlet rates from local sources (MTO 1997; James et al. 2009). Inlet capacity is multiplied by the number of grates as required (e.g. by 2 for a typical road location). This methodology is generally consistent with those from regulatory sources (e.g. MTO); however it does not account for the dynamic changes in inflow with varying head, nor differences in inflow at catchbasins on grade, as compared to catchbasins at sag points. In addition, the application of rating curves can result in model instabilities in locations where minor system surcharge reaches the ground surface (i.e. reverse flows from the minor system back to the major system).

\section{Method 4: Orifices Representing Grates}

In this method, catchbasin grates are represented as bottom-draw orifices. The general layout would again be consistent with that presented in Figure 3. Each catchbasin is assumed to have an approximate opening area of $0.125 \mathrm{~m}^{2}$, based on measurements of standard grate designs used in Ontario (Ontario Provincial Standard Drawings, OPSD, 400.010 and OPSD 400.100; OPS 2016). Similar to method 3 , this opening area is multiplied by the number of grates being represented in the subcatchment, with an equivalent square opening calculated. A standard orifice coefficient of 0.62 is used. This method generally functions more effectively than method 3 in situations where storm sewer surcharge above the surface level is expected (i.e. reverse flow). This method also addresses some of the shortcomings of method 3 by better accounting for the dynamic rate of inflow with varying head (particularly at sag points) and also for permitting reverse flow from the minor system back to the major system. However, this method does not account for any potential inlet restriction provided by the catchbasin lead, as compared to the grate.

\section{Method 5: Dual Orifices Representing Grate and Lead Separately}

In this method, separate orifices are used to represent both the catchbasin grate and the catchbasin lead. A new SWMM junction is thus required which represents the catchbasin structure itself, and links the major system (grate orifice) with the minor system 
(lead orifice). Figure 4 shows this modified layout. Grate orifices (bottom draw) are defined using the approach described in method 4. Catchbasin lead inverts are assumed to be $1.5 \mathrm{~m}$ below the ground surface, with $250 \mathrm{~mm}$ circular leads being assumed for standard catchbasins, and $300 \mathrm{~mm}$ circular leads being assumed for double catchbasins. Both the number of grates and the number of leads are used as multipliers to determine an equivalent opening area. Because of the difficulty of directly multiplying circular areas for the catchbasin leads, an equivalent rectangular area (which maintains the original lead height of $250 \mathrm{~mm}$ or $300 \mathrm{~mm}$ ) is specified for the side draw orifice. A standard orifice coefficient of 0.62 is used for both orifices. This method accounts for the catchbasin lead, which lacked consideration in the preceding methods, and also facilitates the modeling of inlet control devices (ICDs) if required. However, this method is more time consuming to code, and therefore may not be warranted for all studies.

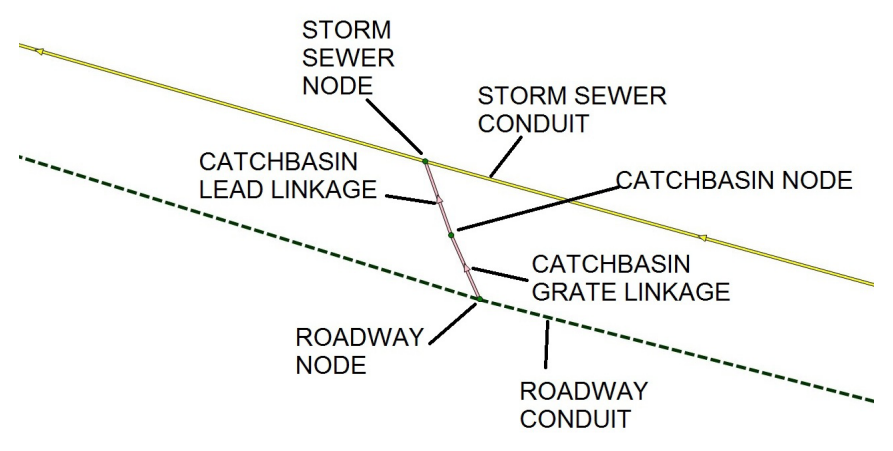

Figure 4 Inlet modeling method 5 (dual orifices).

For the purposes of the current assessment, only the function of catchbasins has been examined. Storm sewer maintenance hole lids may serve as a further connection, linking the minor and major systems, particularly where the open style of grating is specified (OPSD 401.010, Type B; OPS 2016) or where maintenance hole lids are located at lower elevations, closer to the gutter. For the purposes of the current assessment however, these features have been omitted, such that only catchbasins have been included in the comparisons. Sufficient surcharge depth has been added to minor system maintenance holes (where no catchbasins are present) to prevent flow loss and to ensure that the linkage between the minor system and the major system is via catchbasin functions only.

The modeling methods that are assessed for this study are not exhaustive; other methodologies, or variations on those noted may also be considered. However, the methods that are assessed are considered to provide a thorough range of different approaches, and are considered more than sufficient to achieve a robust basis for comparison and to better understand and assess differences between drainage systems and the implications for urban drainage system analysis and design.

\section{Comparison of Simulated Results}

\subsection{General Modeling Methodology}

PCSWMM Professional version 6.3.2223 (32 bit) was used to simulate each of the methods, using EPA-SWMM version 5.1.011. Model results are given for the $2 \mathrm{y}$ or $5 \mathrm{y}$ storm event (whichever is the design basis for the storm sewer system in each of the project examples) and the $100 \mathrm{y}$ storm event (consistent design basis for major overland flow). The locally specified design storm was used for each project example, for each of the previously noted return periods.

Overall model performance metrics have been used as the basis for assessment of the differences between inlet modeling methods. Key metrics to be assessed include:

1. For the minor (storm sewer) system, the number of pipe sections which are unsurcharged, surcharged, or flooded. For the purposes of the current assessment, a section of storm sewer is considered to be surcharged if the simulated hydraulic gradeline $(H G L)$ is above the pipe obvert at either the upstream or downstream end. A section of storm sewer is considered to be flooded if the HGL is above the ground surface at either the upstream or downstream end.

2. For the major (overland flow) system, the number of points which have a simulated maximum flood depth $>0.25 \mathrm{~m}$ (a typical municipal standard for flooding limits; this approximately represents the limits of the roadway right-of-way).

3. For the simulated inlets themselves, the minimum, maximum, and average maximum (overall average of the maxima of all inlets) flows, differentiating for results from catchbasins along the roadway (on grade), catchbasins at sag points, and rear yard catchbasins.

\subsection{Case Study 1 (Shadyglen)}

On 2012-07-22 a significant rainfall event occurred in Hamilton, Ontario. The storm event was centred on Stoney Creek Mountain and the Binbrook area. Rainfall gauges in the affected areas recorded between $90 \mathrm{~mm}$ and $140 \mathrm{~mm}$ of rainfall over a $4 \mathrm{~h}$ time period, during which time as many as 100 area residents reported flooding. Amec Foster Wheeler was retained by the City to undertake a number of investigations related to this area, and ultimately developed dual drainage models for two separate areas affected by the storm event: a portion of the community of Binbrook, and a residential subdivision in the Stoney Creek Mountain known as Shadyglen. The models were calibrated against $1 \mathrm{y}$ of local flow monitoring data (2013). The model development and associated analysis work was summarized in a written report (Amec Environment \& Infrastructure 2014). 
The Shadyglen model that was developed as part of this previous work is used as the first example for the current assessment. The Shadyglen study area is shown in Figure 5.

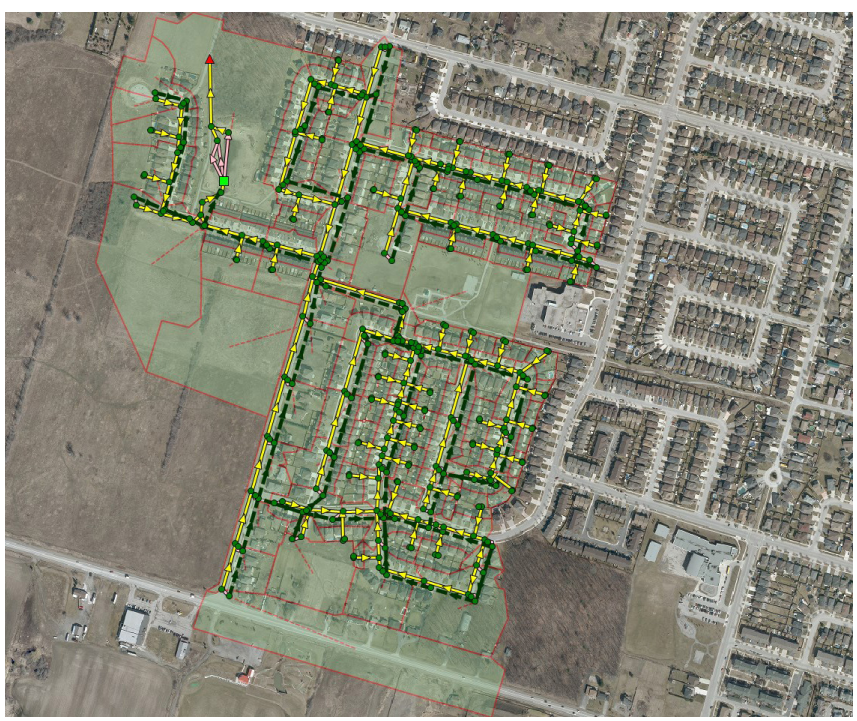

Figure 5 Shadyglen model, Hamilton (Stoney Creek).

The Shadyglen area includes a $\sim 55$ ha drainage area, which consists primarily of single detached residential units, as well as a school and a park area. Drainage is directed to an existing wet pond stormwater management facility (forebay only). The majority of the foundation drains in this area are directly connected to the storm sewer system via gravity drains, and as such are vulnerable to storm sewer surcharging impacts.

The PCSWMM model (Figure 5) developed for Shadyglen, includes 115 subcatchments, which use the United States Soil Conservation Service (U.S. SCS) curve number methodology for the simulation of infiltration. In total, 265 conduits are included in the model, with both minor (storm sewer) and major (roadway) links, and links that have been split to better reflect catchbasin inlet points (e.g. mid-pipe, or not at maintenance holes). There are $\sim 52$ rear yard catchbasins (RYCBs) which are also included in the model. The receiving wet pond SWM facility is included in the model; the boundary condition was set as a normal depth within the receiving storm sewer system downstream.

Dual drainage linkages were originally modeled using method 5 (dual orifices representing grate and lead separately). Orifices were also originally included to model the impacts of open grating style maintenance hole lids. However for the purposes of the current assessment, these linkages have been removed, as discussed in section 1.2 above.

Different versions of the model were developed to reflect the different methods of assessing inlet capacity, as discussed in section 1.2. The City of Hamilton's 6 h Chicago design storm was used for both the $5 \mathrm{y}$ and $100 \mathrm{y}$ return periods. The results are shown in Tables 1 to 3 . Note that the results are focused on roadway inlets only (i.e. RYCB inlets are not included).
Table 1 Simulated 5 y performance for case study 1 .

\begin{tabular}{|c|c|c|c|c|c|c|c|}
\hline \multirow{2}{*}{ Method } & \multirow{2}{*}{$\begin{array}{l}\text { Peak Flow } \\
\text { at Outlet } \\
\left(\mathrm{m}^{3} / \mathrm{s}\right)^{1}\end{array}$} & \multicolumn{3}{|c|}{$\begin{array}{l}\text { Hydraulic Condition of Storm Sewers } \\
\text { (Number of sewer reaches) }\end{array}$} & \multicolumn{3}{|c|}{ Peak Flows for Roadway Inlets $\left(\mathrm{m}^{3} / \mathrm{s}\right)$} \\
\hline & & $\begin{array}{l}\text { Unsur- } \\
\text { charged }\end{array}$ & Surcharged & Flooded & Minimum & Maximum ${ }^{2}$ & $\begin{array}{c}\text { Average } \\
\text { Maximum }^{2}\end{array}$ \\
\hline $1 \mathrm{~A}$ & $2.44(0)$ & 114 & 15 & 0 & NA & NA & NA \\
\hline $1 \mathrm{~B}$ & $2.40(0)$ & 114 & 15 & 0 & 0 & $0.26(0.11)$ & $0.06(0.09)$ \\
\hline 2 & $2.47(0)$ & 113 & 13 & 3 & NA & NA & NA \\
\hline 3 & $2.44(0)$ & 113 & 16 & 0 & 0 & $0.15(0.11)$ & $0.06(0.09)$ \\
\hline 4 & $2.46(0)$ & 115 & 14 & 0 & 0 & $0.10(0.19)$ & $0.05(0.15)$ \\
\hline 5 & $2.47(0)$ & 114 & 15 & 0 & 0 & $0.10(0.19)$ & $0.05(0.15)$ \\
\hline
\end{tabular}

Table 2 Simulated 100 y performance for case study 1.

\begin{tabular}{|c|c|c|c|c|c|c|c|}
\hline \multirow{2}{*}{ Method } & \multirow{2}{*}{$\begin{array}{l}\text { Peak Flow } \\
\text { at Outlet } \\
\left(\mathrm{m}^{3} / \mathrm{s}\right)^{1}\end{array}$} & \multicolumn{3}{|c|}{$\begin{array}{l}\text { Hydraulic Condition of Storm Sewers } \\
\text { (Number of sewer reaches) }\end{array}$} & \multicolumn{3}{|c|}{ Peak Flows for Roadway Inlets $\left(\mathrm{m}^{3} / \mathrm{s}\right)$} \\
\hline & & $\begin{array}{l}\text { Unsur- } \\
\text { charged }\end{array}$ & Surcharged & Flooded & Minimum & Maximum $^{2}$ & $\begin{array}{c}\text { Average } \\
\text { Maximum }^{2}\end{array}$ \\
\hline $1 \mathrm{~A}$ & $4.48(0.56)$ & 0 & 106 & 22 & NA & NA & NA \\
\hline $1 \mathrm{~B}$ & $4.52(0.87)$ & 0 & 73 & 55 & -0.35 & $0.51(0.95)$ & $0.16(0.68)$ \\
\hline 2 & NA & NA & NA & NA & NA & NA & NA \\
\hline 3 & $4.45(1.54)$ & 0 & 46 & 82 & -0.10 & $0.20(0.20)$ & $0.11(0.20)$ \\
\hline 4 & $4.72(1.83)$ & 0 & 41 & 87 & -0.08 & $0.22(0.82)$ & $0.10(0.59)$ \\
\hline 5 & $4.39(1.95)$ & 0 & 55 & 73 & -0.04 & $0.22(0.29)$ & $0.10(0.28)$ \\
\hline
\end{tabular}

Table 3 Simulated 100 y ponding depths for case study 1.

\begin{tabular}{ccc}
\hline Method & $\begin{array}{c}\text { Major System Nodes with } \\
\text { Simulated Depth }<0.25 \mathrm{~m}\end{array}$ & $\begin{array}{c}\text { Major System Nodes with } \\
\text { Simulated Depth }>0.25 \mathrm{~m}^{1}\end{array}$ \\
\hline 1A & 74 & $1(1)$ \\
1B & 74 & $1(1)$ \\
2 & NA & NA \\
3 & 69 & $6(2)$ \\
4 & 68 & $7(2)$ \\
5 & 70 & $5(2)$ \\
\hline
\end{tabular}

'First value represents total number, bracketed value indicates the number of which are sag points.

For the simulation of the $5 \mathrm{y}$ storm event (design criterion for the storm sewer system), all of the tested methods yield similar results with respect to the peak flow at the outlet (Table 1) and the number of conduits which are identified as being surcharged. Method 2 ( 5 y inlet capacity) results in 3 conduits being indicated as flooded. Methods $1 \mathrm{~A}$ and $1 \mathrm{~B}$ (no inlet capacity restriction) notably do not result in any simulated storm sewer flooding; this difference, compared to method 2, is due to the lack of an inlet for one upstream section of pipe. With respect to inlet flows, method $1 \mathrm{~B}$ yields the highest flows as would be expected (given the oversized inlets in this scenario). Maximum 
flows for method 3 yield somewhat counterintuitive results, with the highest flow being indicated for an on-grade inlet, rather than at a sag point. This appears to be due to differences in the maximum simulated roadway depths, and the sensitivity of the rating curve to this value (full flow is not assumed until a depth of $0.03 \mathrm{~m}$ ). This parameter appears to be particularly sensitive, and should therefore be reviewed with caution in model development. Methods 4 and 5 yield more intuitively consistent results, with sag points indicating the highest inflow rates, as would be expected.

No 100 y storm event results are presented for method 2 (5 y inlet capacity). Initial modeling for this method involved the input of steady flows (100 y flow less assumed $5 \mathrm{y}$ sewer flow) into a major-system-only model. However, due to the use of steady flows, hydrograph routing and timing effects are not properly accounted for, resulting in excessively large simulated total flows. Full hydrographs could be input as an alternative (manually deducting the $5 \mathrm{y}$ flow), but this is extremely onerous. An alternative would be to use divider functions in SWMM. However, this would require the use of kinematic wave routing (in lieu of the more robust dynamic wave routing), and as such may not yield a direct comparison to the other methods assessed.

For the simulation of the $100 \mathrm{y}$ storm event (design criterion for the major system), simulated peak flows at the outlet (Table 2 ) are again generally similar between the various methods. Of interest is that methods $1 \mathrm{~A}$ and $1 \mathrm{~B}$ (no inlet capacity restriction) yield the lowest number of simulated flooded storm sewers. It could be assumed that with no inlet restrictions the storm sewer system would be surcharged to the maximum amount possible. However, based on a review of the modeled results, this result is due to the large openings assumed for RYCBs, which provide a greater degree of trunk sewer flow relief than is given in the other methods, in which the connection to surface storage above RYCBs is much more restricted. Conversely, methods $1 \mathrm{~A}$ and $1 \mathrm{~B}$ yield the lowest number of flooded surface nodes (>0.25 $\mathrm{m}$ depth as shown in Table 3), while methods 3, 4 and 5 yield similar results.

With respect to simulated inlet capacity under the $100 \mathrm{y}$ storm event (Table 2), all of the methods assessed present some negative flows, which indicates reverse flow conditions (storm sewer surcharge contributing flow to the surface). Method 1B indicates the highest negative flow, which again reflects the oversized inlets in this scenario. Method 3 indicates the next highest negative flows, which is notable considering that flows are specified by a surface based rating curve relative to depths above the catchbasin. Model results indicate that these negative flows do reflect a period when the minor system head exceeds the head at the corresponding major node. However the resulting hydrograph indicates some abrupt transitions during this period due to the definition of the curve. With respect to maximum simulated inlet capacity, the highest flows are indicated at sag points for all methods, which is reasonable. The highest inlet flow rates are again indicated for method $1 \mathrm{~B}$, as would be expected.
Of note is the variability in the maximum simulated inlet rates at sag points between methods 3, 4 and 5 . As in the rating curve definition, method 3 is restricted to a maximum discharge of $0.20 \mathrm{~m}^{3} / \mathrm{s}$ (50 L/s each for two double catchbasins). According to MTO Design Chart 4.19 (MTO 1997), actual inflow rates at sag points would be expected to be much higher: up to $0.80 \mathrm{~m}^{3} / \mathrm{s}$ for two double catchbasins at a head of $0.3 \mathrm{~m}$. This is notable, and is discussed further in section 2.5. For the two orifice-based methods (methods 4 and 5), the difference in maximum flow rate at the sag points is notable $\left(0.82 \mathrm{~m}^{3} / \mathrm{s}\right.$ for method 4 and $0.29 \mathrm{~m}^{3} / \mathrm{s}$ for method 5). This difference can be attributed to the attenuation provided by the catchbasin lead, and its importance in more accurately simulating inlet capacity at sag points in particular (as shown in Table 2, the difference is not as noticable for catchbasins on grade). An example of the $100 \mathrm{y}$ storm event inflow hydrographs at the primary sag point are shown in Figure 6. The restriction of inflow for method 3 is clearly evident, as is the reduced inflow for method 5 as compared to method 4.

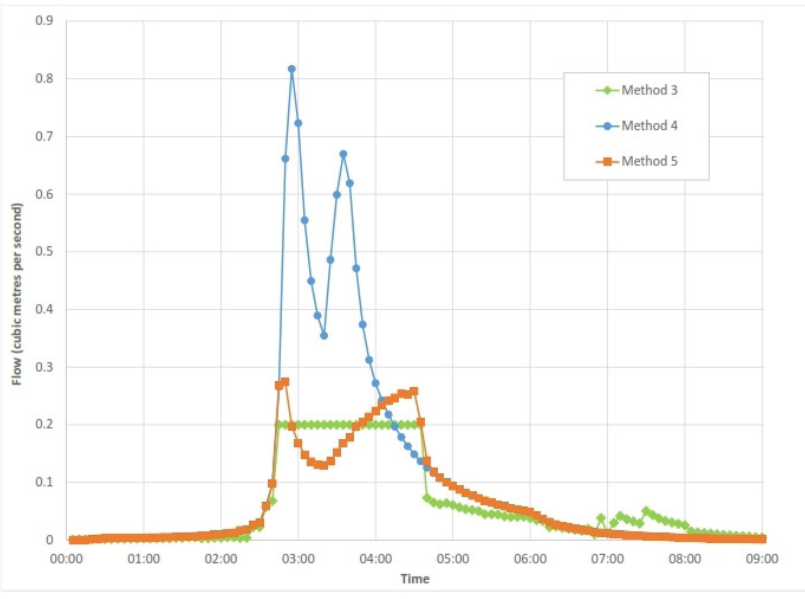

Figure $6100 \mathrm{y}$ storm event inlet hydrographs at Shadyglen sag point.

\subsection{Case Study 2 (South Pelham)}

A rain on snow event in December 2013 in Welland resulted in a surcharging of the stormwater collection system within the South Pelham subdivision. The surcharge ultimately led to an overflow from one of the lowest rear yard catchbains (RYCBs), which in turn resulted in surface flooding on an adjacent property. A number of reviews were subsequently conducted by the City of Welland, as well as by an external consultant (GM BluePlan Engineering Limited 2014). While both the rain on snow nature of the event and the SWM facility outlet blockage were cited as contributing factors, lower RYCB elevations were also noted as a concern, as were the capacity and operating levels of the existing SWM facility. Amec Foster Wheeler was retained in 2016 to develop a dynamic hydrologic-hydraulic model of the development's drainage system to further assess the expected performance of the area drainage system, as well as to assess potential mitigation measures. Further, the study included the simulation of a number 
of climate change scenarios by using projected future rainfall intensity-duration-frequency (IDF) curves. At the time of writing the study is currently in progress, and is expected to be completed by mid 2017.

The South Pelham model developed as part of this work has been used as case study 2 . The South Pelham study area is shown in Figure 7.

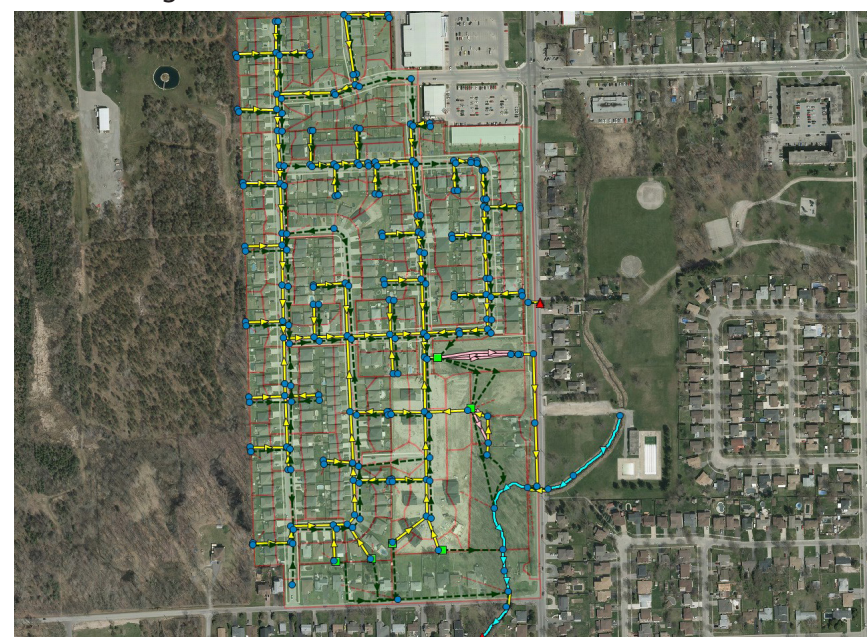

Figure 7 South Pelham model, Welland.

The South Pelham area includes a $\sim 26$ ha drainage area, which consists primarily of single detached residential units. Drainage is directed to an existing wet pond SWM facility. Foundation drains for this area are understood to be serviced by sump pumps discharging to grade.

The PCSWMM model that was developed for the South Pelham subdivision (Figure 6), includes 96 subcatchments, which use the U.S. SCS curve number methodology for the simulation of infiltration. In total, 232 conduits have been included in the model, which includes both minor (storm sewer) and major (roadway) links, and which accounts for links that have been split to better reflect catchbasin inlet points (i.e. mid-pipe, not at maintenance holes). There are 37 RYCBs, which have been included in the model. The receiving wet pond SWM facility has been incorporated into the model, including the outlet pipe. The model used for the current assessment is a simplified version of the original model. Under typical operating conditions, tailwater influences both from the SWM facility and from the downstream receiving water (Drapers Creek) would have a significant impact upon drainage system performance. For the purposes of the current modeling, however, these features have not been included; rather, normal boundary conditions have been assumed at the SWM facility inlets and outlets. This allows for a more direct assessment of inlet modeling methods by limiting external factors.

In the original model, dual drainage linkages were coded using method 4 (orifices representing catchbasin grates). Orifices were also originally included to model the impacts of open grating style maintenance hole lids; however, for the purposes of the current assessment, these linkages have been removed, as discussed in section 1.2 above.

Different versions of the model have been developed to reflect the different methods of assessing inlet capacity, as shown in section 1.2. Similar to case study 1, a $6 \mathrm{~h}$ Chicago design storm was used, using currently approved IDF data from the City of Welland. The $2 \mathrm{y}$ storm event was used for simulation of the minor system, given that this is the governing design standard in the city (City of Welland 2013). The 100 y storm event was used for the assessment of major system flows. The results are given in Tables 4 to 6 . Note that the results are for roadway inlets only (i.e. RYCB inlets are not included).

Table 4 Simulated 2 y performance for case study 2.

\begin{tabular}{|c|c|c|c|c|c|c|c|}
\hline \multirow{2}{*}{ Method } & \multirow{2}{*}{$\begin{array}{c}\text { Peak Flow } \\
\text { at Outlet } \\
\left(\mathrm{m}^{3} / \mathrm{s}\right)^{1}\end{array}$} & \multicolumn{3}{|c|}{$\begin{array}{l}\text { Hydraulic Condition of Storm Sewers } \\
\text { (Number of sewer reaches) }\end{array}$} & \multicolumn{3}{|c|}{ Peak Flows for Roadway Inlets ( $\mathrm{m}^{3} / \mathrm{s}$ ) } \\
\hline & & $\begin{array}{l}\text { Unsur- } \\
\text { charged }\end{array}$ & Surcharged & Flooded & Minimum & Maximum $^{2}$ & $\begin{array}{c}\text { Average } \\
\text { Maximum }^{2}\end{array}$ \\
\hline $1 \mathrm{~A}$ & $1.42(0)$ & 0 & 60 & 0 & NA & NA & NA \\
\hline $1 \mathrm{~B}$ & $1.47(0)$ & 0 & 60 & 0 & 0 & $0.07(0.08)$ & $0.03(0.06)$ \\
\hline 2 & $1.46(0)$ & 0 & 60 & 0 & NA & NA & NA \\
\hline 3 & $1.65(0)$ & 0 & 54 & 6 & 0 & $0.06(0.14)$ & $0.04(0.08)$ \\
\hline 4 & $1.75(0)$ & 0 & 54 & 6 & -0.01 & $0.04(0.10)$ & $0.02(0.07)$ \\
\hline 5 & $1.55(0)$ & 0 & 60 & 0 & 0 & $0.04(0.10)$ & $0.02(0.07)$ \\
\hline
\end{tabular}

Table 5 Simulated 100 y performance for case study 2.

\begin{tabular}{|c|c|c|c|c|c|c|c|}
\hline \multirow{2}{*}{ Method } & \multirow{2}{*}{$\begin{array}{c}\text { Peak Flow } \\
\text { at Outlet } \\
\left(\mathrm{m}^{3} / \mathrm{s}\right)^{1}\end{array}$} & \multicolumn{3}{|c|}{$\begin{array}{l}\text { Hydraulic Condition of Storm Sewers } \\
\text { (Number of sewer reaches) }\end{array}$} & \multicolumn{3}{|c|}{ Peak Flows for Roadway Inlets $\left(\mathrm{m}^{3} / \mathrm{s}\right)$} \\
\hline & & $\begin{array}{l}\text { Unsur- } \\
\text { charged }\end{array}$ & Surcharged & Flooded & Minimum & Maximum² & $\begin{array}{l}\text { Average } \\
\text { Maximum }^{2}\end{array}$ \\
\hline $1 \mathrm{~A}$ & $2.16(0)$ & 0 & 57 & 3 & $\overline{N A}$ & NA & NA \\
\hline $1 \mathrm{~B}$ & $2.14(0)$ & 0 & 23 & 37 & -0.07 & $0.18(0.18)$ & $0.07(0.13)$ \\
\hline 2 & NA & NA & NA & NA & NA & NA & NA \\
\hline 3 & $2.16(0)$ & 0 & 23 & 37 & -0.09 & $0.10(0.20)$ & $0.07(0.17)$ \\
\hline 4 & $2.20(0)$ & 0 & 22 & 38 & -0.06 & $0.20(0.24)$ & $0.04(0.16)$ \\
\hline 5 & $2.18(0)$ & 0 & 22 & 38 & -0.04 & $0.14(0.18)$ & $0.04(0.14)$ \\
\hline
\end{tabular}

Table 6 Simulated 100 y ponding depths for case study 2.

\begin{tabular}{ccc}
\hline Method & $\begin{array}{c}\text { Major System Nodes with } \\
\text { Simulated Depth }<0.25 \mathrm{~m}\end{array}$ & $\begin{array}{c}\text { Major System Nodes with } \\
\text { Simulated Depth }>0.25 \mathrm{~m}^{1}\end{array}$ \\
\hline 1A & 59 & $4(3)$ \\
1B & 60 & $3(2)$ \\
2 & $\mathrm{NA}$ & $\mathrm{NA}$ \\
3 & 59 & $4(3)$ \\
4 & 57 & $6(5)$ \\
5 & 58 & $5(4)$ \\
\hline
\end{tabular}

'First value represents total number, bracketed value indicates the number of which are sag points. 
For the simulation of the $2 \mathrm{y}$ storm event (design criterion for the storm sewer system in Welland), the tested methods yield generally similar results with respect to the peak flow at the outlet (Table 4) and the number of conduits which are identified as being surcharged. Methods 3 and 4 yield somewhat higher flows as compared to the other methods, and also result in 6 conduits flooding for the 2 y event (all other methods indicate surcharging, but no flooding). This is again somewhat counter-intuitive, given that methods $1 \mathrm{~A}$ and $1 \mathrm{~B}$ would be expected to yield the highest sewer flows and corresponding sewer surcharging and flooding, given the lack of inlet controls under this scenario. This result appears to be due to the timing of flows and tailwater impacts. Simulated roadway inlet flows are more consistent among all methods, with the highest flows being consistently simulated at roadway sag points, as would be expected.

Consistent with case study 1 , no results are given for the 100 y storm event for method 2 ( 2 y storm sewer inlet capacity). For the simulation of the $100 \mathrm{y}$ storm event (design criteria for the major system), simulated peak flows at the outlet (Table 5) are again generally similar between the various methods. Consistent with case study 1 , method $1 \mathrm{~A}$ (no inlet restriction or inlet functions) yields the lowest number of simulated flooded storm sewers; it would be assumed that with no inlet restrictions the storm sewer system would be surcharged to the maximum amount possible. Conversely, method 1B (no inlet restriction-oversized inlets) yields results much more consistent with the other simulated methods. This may reflect that while inlets are considered oversized in method $1 \mathrm{~B}$, the overall approach is more consistent with methods 3, 4 and 5; method 1A does not include any form of inlet function directly.

With respect to simulated inlet capacity under the $100 \mathrm{y}$ storm event (Table 5), all of the methods assessed show some negative flows, which indicates reverse flow conditions (storm sewer surcharge contributing flows back to the surface). The highest simulated negative flows are for method 3, which is notable considering that flows are specified by a surface-based rating curve relative to depths above the catchbasin. The model results indicate that these negative flows reflect a period when the minor system head exceeds the head at the corresponding major node; however, the resulting hydrograph indicates model oscillations (similar to case study 1), likely due to the definition of the curve (positive heads only) and the model sensitivity to the rating curve defintions. The highest simulated inlet flows are again indicated at sag points for all methods, which is reasonable.

According to the rating curve definition, inlet flows using method 3 are restricted to a maximum discharge of $0.20 \mathrm{~m}^{3} / \mathrm{s}$ ( $50 \mathrm{~L} / \mathrm{s}$ for each of two double catchbasins). As noted earlier, according to MTO Design Chart 4.19 (MTO 1997), actual inflow rates at sag points would be expected to be much higher: up to $0.80 \mathrm{~m}^{3} / \mathrm{s}$ for two double catchbasins at a head of $0.3 \mathrm{~m}$. This is notable, and discussed further in section 2.5 below.

For the two orifice-based methods (methods 4 and 5), the difference in maximum flow rate at the sag points is negligible $\left(0.24 \mathrm{~m}^{3} / \mathrm{s}\right.$ for method 4 and $0.18 \mathrm{~m}^{3} / \mathrm{s}$ for method 5$)$. The reduced inflow for method 5 is again attributed to the attenuation provided by the catchbasin lead, and its importance in more accurately simulating inlet capacity at sag points in particular (as shown in Table 5, the difference is not as noticeable for catchbasins on grade). Method 1B (oversized inlets and no inlet restriction) yields slightly lower sag discharges than methods 3 and 4; the difference is, however, considered slight, and likely due to flow timing and the splitting of flows between the minor and major system upstream of sag points. Figure 8 presents the inflow hydrographs at a sag point for the $100 \mathrm{y}$ storm event, for methods 3, 4 and 5 . As evident, method 3 restricts the inflow to the specified maximum, while methods 4 and 5 indicate more complete hydrographs, with method 5 yielding somewhat lower inflows.

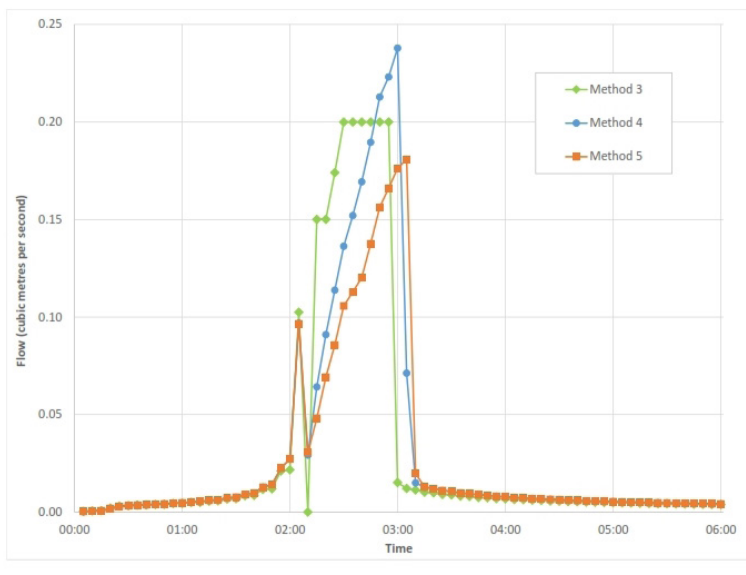

Figure 8100 y storm event inlet hydrographs at South Pelham sag point.

The $100 \mathrm{y}$ surface ponding depths are generally consistent among the assessed methods; a slightly higher number of nodes ponded $>0.25 \mathrm{~m}$ for methods 4 and 5 , which reflects the additional inlet restriction for these scenarios (which results in greater surface flows and ponding depths).

\subsection{Case Study 3 (York Road)}

York Road is an urban arterial roadway in Guelph, between the eastern limits of the city and the downtown core. Amec Foster Wheeler Environment \& Infrastructure was retained by the City of Guelph in 2015 to provide detailed design services for a roadway reconstruction, including subsurface utilities. The proposed re-construction was to include a revised surface layout, which provided dedicated bike lanes and onstreet parking areas. The roadway is located in an older area of the city, close to the downtown core; as such no environmental approvals existed for the existing sub-surface utilities, and no stormwater quantity or quality measures were in place.

As a case study, modeling York Road offers a different type of application (road reconstruction as compared to the forensic flood assessments and remediation strategies of case studies 1 and 2). The York Road model that was developed as part of this 
work is used as an example for the current assessment. The York Road study area is shown in Figure 9.

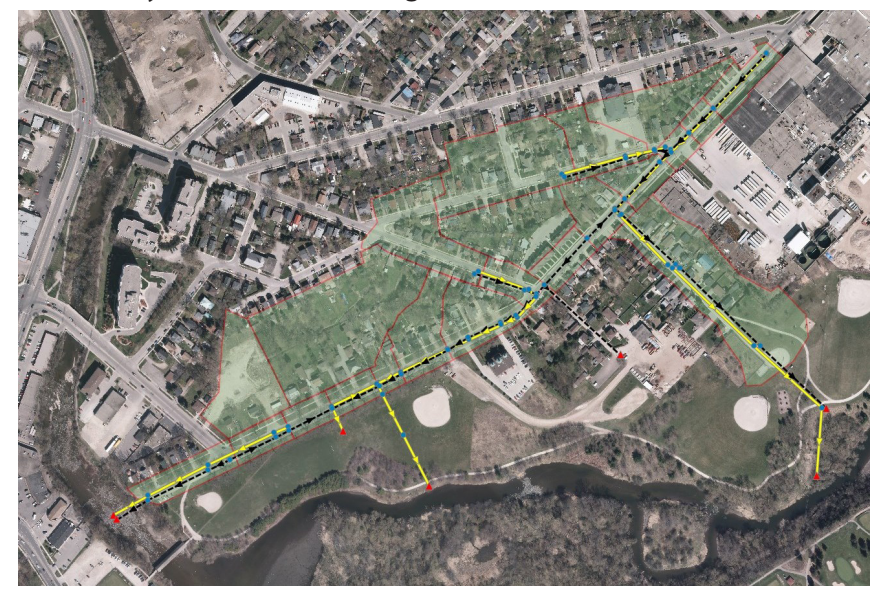

Figure 9 York Road model, Guelph.

The York Road area of interest includes a $\sim 14$ ha drainage area, which consists primarily of single detached residential units. Drainage is directed to three different primary outfalls; one at the western limits of the study area, a central outfall through a public park, and an outfall through a second park at the eastern limits, at the end of a residential street. The westerly outfall discharges to the Speed River while the two easterly outfalls discharge to the tributary Eramosa River. Foundation drainage for the majority of the development is understood to be through separated sump pumps (not connected to the storm sewer system).

The PCSWMM model developed for the York Road study area (Figure 7) reflects the originally proposed conditions. Road and storm sewer reconstruction for this project was completed in late 2016. This model was selected because under pre-construction conditions the storm sewer system was substantially undersized. Under a post-construction condition only a 2 y storm design capacity could be achieved due to grading restrictions, primarily at the existing outfalls to the Eramosa River. Further, in order to set reasonable tailwater conditions for a case study example, it was assumed for the purpose of the model that storm sewer upgrades downstream (not part of the reconstruction project) were in place to allow for unsurcharged conveyance of the design event ( 2 y storm). In addition, it was assumed that under more formative events tailwater from the watercourse receiver (Eramosa River) would have an impact on drainage system performance. For the purposes of the current assessment, a normal boundary condition was used at outfalls.

The PCSWMM model includes 22 subcatchments, and uses the Green-Ampt method for the simulation of infiltration, consistent with the approach used in the original Stormwater Management Master Plan (AMEC Environment \& Infrastructure 2012). In total, 66 conduits are included in the model, which includes both minor (storm sewer) and major (roadway) links, and accounts for links that have been split to better reflect catchbasin inlet points (i.e. mid-pipe, not at maintenance holes). The roadway reconstruction used side inlet catchbasins; however, in order to provide a reasonable comparison to case studies 1 and 2 (and given the lack of Ministry of Transportation, MTO, rating curves for side inlet catchbasins), standard bottom draw catchbasins have been used in the modeling.

In the original modeling, dual drainage linkages were coded using method 4 (orifices representing catchbasin grates). Orifices were also originally included to model the impacts of maintenance hole lids; however for the purposes of the current assessment, these linkages have been removed, as discussed in section 1.2 above.

Different versions of the model have been developed to reflect the different methods of assessing inlet capacity, as described in section 1.2 above. The City of Guelph's standard $3 \mathrm{~h}$ Chicago design storms were used for the estimation of flows. The 2 y storm event was used for simulation of the minor system because that is what was used as the design standard for the reconstruction (Guelph's standard is a $5 \mathrm{y}$ event; however, this could not be achieved in practice due to grading restrictions). The $100 \mathrm{y}$ storm event was used for the assessment of major system flows. The results are shown in Tables 7 to 9. Peak flow results are included only for the two outlets to the Eramosa River as these were the focus of the reconstruction.

Table 7 Simulated 2 y performance for case study 3.

\begin{tabular}{|c|c|c|c|c|c|c|c|c|}
\hline \multirow[t]{2}{*}{ Method } & \multirow{2}{*}{$\begin{array}{c}\text { Peak Flow } \\
\text { at West } \\
\text { Outlet } \\
\left(\mathrm{m}^{3} / \mathrm{s}\right)^{1}\end{array}$} & \multirow{2}{*}{$\begin{array}{l}\text { Peak Flow } \\
\text { at East } \\
\text { Outlet } \\
\left(\mathrm{m}^{3} / \mathrm{s}\right)^{1}\end{array}$} & \multicolumn{3}{|c|}{$\begin{array}{l}\text { Hydraulic Condition of Storm } \\
\text { Sewers (Number of sewer } \\
\text { reaches) }\end{array}$} & \multicolumn{3}{|c|}{$\begin{array}{l}\text { Peak Flows for Roadway Inlets } \\
\qquad\left(\mathrm{m}^{3} / \mathrm{s}\right)\end{array}$} \\
\hline & & & $\begin{array}{l}\text { Unsur- } \\
\text { charged }\end{array}$ & $\begin{array}{c}\text { Sur- } \\
\text { charged }\end{array}$ & Flooded & Minimum & Maximum $^{2}$ & $\begin{array}{c}\text { Average } \\
\text { Maximum }^{2}\end{array}$ \\
\hline $1 \mathrm{~A}$ & $0.25(0)$ & $0.33(0)$ & 28 & 4 & 0 & NA & NA & NA \\
\hline $1 \mathrm{~B}$ & $0.26(0)$ & $0.29(0)$ & 28 & 4 & 0 & 0 & $0.09(0.09)$ & $0.03(0.05)$ \\
\hline 2 & $0.25(0)$ & $0.32(0)$ & 28 & 4 & 0 & NA & NA & NA \\
\hline 3 & $0.27(0)$ & $0.31(0)$ & 29 & 3 & 0 & 0 & $0.09(0.10)$ & $0.03(0.05)$ \\
\hline 4 & $0.25(0)$ & $0.28(0)$ & 31 & 1 & 0 & 0 & $0.05(0.07)$ & $0.02(0.05)$ \\
\hline 5 & $0.20(0)$ & $0.28(0)$ & 29 & 3 & 0 & 0 & $0.05(0.08)$ & $0.02(0.07)$ \\
\hline
\end{tabular}

Table 8 Simulated 100 y performance for case study 3.

\begin{tabular}{|c|c|c|c|c|c|c|c|c|}
\hline \multirow[t]{2}{*}{ Method } & \multicolumn{5}{|c|}{$\begin{array}{l}\text { Peak Flow at Peak Flow at Hydraulic Condition of Storm } \\
\text { West Outlet } \\
\begin{array}{ccc}\left(\mathrm{m}^{3} / \mathrm{s}\right)^{1} & \left(\mathrm{~m}^{3} / \mathrm{s}\right)^{1} & \text { reaches) }\end{array}\end{array}$} & \multicolumn{3}{|c|}{$\begin{array}{l}\text { Peak Flows for Roadway Inlets } \\
\qquad\left(\mathrm{m}^{3} / \mathrm{s}\right)\end{array}$} \\
\hline & & & $\begin{array}{l}\text { Unsur- } \\
\text { charged }\end{array}$ & $\begin{array}{c}\text { Sur- } \\
\text { charged }\end{array}$ & Flooded & Minimum & Maximum² & $\begin{array}{c}\text { Average } \\
\text { Maximum² }\end{array}$ \\
\hline $1 \mathrm{~A}$ & $0.48(0.12)$ & $0.59(0.40)$ & 0 & 28 & 4 & NA & NA & NA \\
\hline $1 B$ & $0.41(0.17)$ & $0.58(0.34)$ & 0 & 8 & 24 & -0.01 & $0.24(0.42)$ & $0.11(0.16)$ \\
\hline 2 & NA & NA & NA & NA & NA & NA & NA & NA \\
\hline 3 & $0.37(0.30)$ & $0.48(0.89)$ & 0 & 16 & 16 & -0.04 & $0.17(0.20)$ & $0.07(0.14)$ \\
\hline 4 & $0.40(0.29)$ & $0.58(0.44)$ & 0 & 15 & 17 & 0 & $0.20(0.41)$ & $0.07(0.17)$ \\
\hline 5 & $0.40(0.28)$ & $0.57(0.41)$ & 0 & 22 & 10 & 0 & $0.23(0.36)$ & $0.07(0.20)$ \\
\hline
\end{tabular}


Table 9 Simulated 100 y ponding depths for case study 3.

\begin{tabular}{lcc}
\hline Method & $\begin{array}{c}\text { Major System Nodes with } \\
\text { Simulated Depth }<0.25 \mathrm{~m}\end{array}$ & $\begin{array}{c}\text { Major System Nodes with } \\
\text { Simulated Depth }>0.25 \mathrm{~m}^{1}\end{array}$ \\
\hline $1 \mathrm{~A}$ & 29 & $2(2)$ \\
$1 \mathrm{~B}$ & 28 & $3(3)$ \\
2 & $\mathrm{NA}$ & $\mathrm{NA}$ \\
3 & 28 & $3(3)$ \\
4 & 28 & $3(3)$ \\
5 & 28 & $3(3)$ \\
\hline
\end{tabular}

'First value represents total number, bracketed value indicates the number of which are sag points.

For the simulation of the $2 \mathrm{y}$ storm event (design criterion for the storm sewer system), the tested methods again yield generally similar results with respect to the peak flows at the two outlets considered (Table 7) and the number of conduits which are identified as being surcharged. Method 4 resulted in the lowest number of simulated surcharged conduits; however, the difference is considered to be slight. Simulated roadway inlet flows are more consistent among all methods, with the highest flows being consistently simulated at roadway sag points, as would be expected.

Consistent with the other two case studies, no results are shown for the 100 y storm event for method 2 ( 2 y storm sewer inlet capacity). For the simulation of the $100 \mathrm{y}$ storm event (design criterion for the major system), simulated peak flows at the two identified outlets (Table 8 ) are again generally similar for the various methods. Consistent with case study 1 , method $1 \mathrm{~A}$ (no inlet restriction or inlet functions) yields the lowest number of simulated flooded storm sewers; it would be assumed that with no inlet restrictions the storm sewer system would be surcharged to the maximum amount possible. Conversely, Method 1B (no inlet restriction-oversized inlets) yields results more consistent with the other methods, and has the largest number of simulated flooded conduits, which is to be expected given the lack of simulated inlet controls. Method 5 (representation of both the catchbasin grate and catchbasin lead) has the lowest number of simulated flooded conduits (other than method $1 \mathrm{~A}$ ), which reflects the inlet restrictions accounted for in this approach.

With respect to simulated inlet capacity under the $100 \mathrm{y}$ storm event (Table 8), negative flows (which indicate reverse flow conditions-storm sewer surcharge contributing flows to surface runoff) are noted only for methods $1 B$ and 3 (but not for methods 4 and 5). This may reflect a greater magnitude of storm sewer surcharging or flooding, which are the typical causes of reverse flow, under these scenarios. The highest simulated inlet flows are again indicated at sag points for all methods, which is reasonable.

According to the rating curve definition, inlet flows using method 3 are restricted to a maximum discharge of $0.20 \mathrm{~m}^{3} / \mathrm{s}$ ( $50 \mathrm{~L} / \mathrm{s}$ for each of two double catchbasins). For the orifice-based methods (1B, 4 and 5), simulated sag point inflows are notably higher $\left(\leq 0.42 \mathrm{~m}^{3} / \mathrm{s}\right)$ which reflects the ability of orifices to vary discharge with varying head (as would be expected). The somewhat reduced inflow for method 5 is again attributed to the attenuation provided by the catchbasin lead, and its importance in more accurately simulating inlet capacity at sag points in particular (as shown in Table 8, the difference is not as noticeable for catchbasins on grade). Hydrographs for methods 3, 4 and 5 at a roadway sag point are shown in Figure 10 . The instability of method 3 (oscillations) is evident in this case, as is the restricted inflow rate of $0.20 \mathrm{~m}^{3} / \mathrm{s}$. Inflows for methods 4 and 5 yield generally consistent results, with a slightly reduced inflow for method 5 as noted previously.

The 100 y surface ponding depths are generally consistent amongst the assessed methods (Table 9).

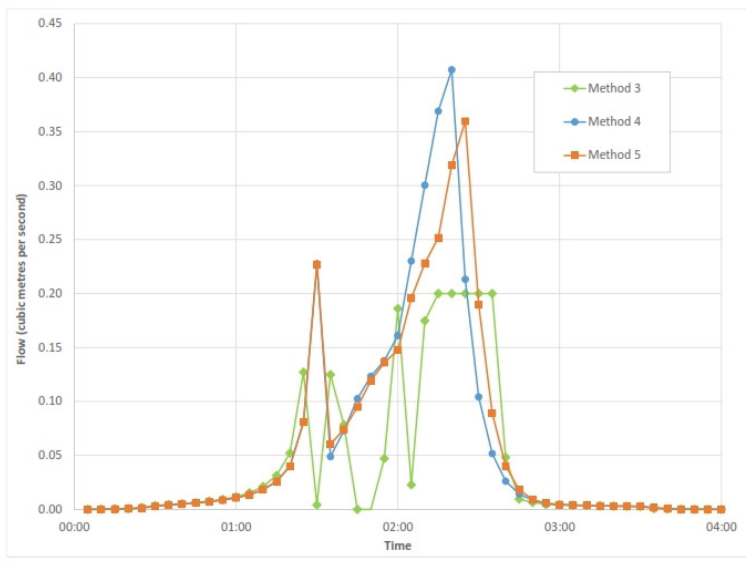

Figure $10100 \mathrm{y}$ storm event inlet hydrographs at York Road sag point.

\subsection{Overall Findings}

The three case studies assessed as part of this paper have allowed for a comparison of several different storm sewer inlet modeling methodologies. It is proposed that a better understanding of the differences of available methods is important in selecting an appropriate and defensible approach that yields a reasonable approximation of the performance and operation of the actual storm sewer system.

In general, the modeling results indicate that for the more frequent, less formative storm events (i.e. design of the minor system, 2 y or 5 y return period), simulated differences are generally nominal. A more significant difference is evident if the minor (storm sewer) system is undersized, as is the situation for case study 2 in particular.

Consideration of an appropriate inlet modeling methodology appears to be more significant for less frequent, more formative storm events (e.g. design of the major system, $100 \mathrm{y}$ return period). In this case, depths of surface ponding and exceedance of the minor system capacity show that the inlet function is of key importance in determining how these two systems interact. The three case studies assessed in this paper indicated more notable differences between methodologies for the 100 y storm event, including differences in inlet capacity flows as well as the resulting 
simulated performance of both the minor and major drainage systems.

While method 1 (no inlet restriction) and method 2 (inlet capacity equal to the design capacity of the minor system) yield useful results for comparison, it is considered that ultimately these methods are not realistic. Method 1 would result in an underestimation of major system ponding during formative events, as indicated in the modeled results (particularly for case study 1). Method 2 also neglects the expected surcharge of the minor system during more formative events, which could be particularly problematic in cases where foundation drainage is connected to the storm sewer system. Method 2 would conservatively overestimate major system flows. However, this approach is considered difficult to model in SWMM using a dynamic wave methodology (with externally input steady flows). This approach may be feasible using the kinematic wave methodology and SWMM dividers, provided that the system hydraulics are relatively simplified (i.e. there is no reverse or pressure flow).

In general, it is proposed that method 3 (rating curve), method 4 (orifices representing catchbasin grates), and method 5 (dual orifices separately representing catchbasin grates and leads) are the most reasonable and most defensible approaches to modeling catchbasin features and functions in dual drainage modeling in SWMM.

Nonetheless, a number of concerns have been noted with the use of method 3. This method was found to be particularly sensitive to the rating curve definition and the specification of the first depth ordinate. Unacceptably high modeling continuity errors were noted at lower depth ordinates, suggesting that a higher ordinate is required to ensure a smoother modeling transition. This issue could be addressed through the implementation of actual rating curves from laboratory testing (MTO 1989); however, such an approach could be more time consuming to implement and code. Model oscillations and irregular hydrographs and hydraulic gradeline plots were noted frequently with method 3, which further suggests that caution is required with this approach. Actual rating curves would also need to indicate the significant difference in performance between at-grade inlets and those within sag points. As noted in the case studies, method 3 tended to result in maximization of the inlet capacity (flatlining) which did not correspond to actual testing data, or the common expectation of increasing inflows with increasing head. Finally, method 3 is based on the assumption of positive flow (drainage through the catchbasin grate into the storm sewer). This method is not as well suited as other methods for more complex conditions such as reverse flow (storm sewer flooding back to the surface), as may be the case in some areas, particularly older development areas.

It is therefore suggested that methods 4 (orifices representing inlet grates) and 5 (orifices representing inlet grates and leads) are the more robust approaches, as these methods explicitly account for the physical grate opening size, and more readily allow for complex hydraulic conditions such as reverse flow (storm sewer flooding to the surface). By better representing the physical inlet restriction, minor (storm sewer) system surcharging is not overestimated, and major (overland flow) system flooding and ponding is not underestimated. This is evident from the results from the three case studies assessed in this study.

Method 5 is proposed as the most robust modeling approach, by accounting for the secondary restriction of the catchbasin lead. As evident from the case study results, consideration of the hydraulic behaviour of the catchbasin lead typically results in reduced maximum inlet capacity, but, in contrast, in no significant change (or even in some cases a reduction) in major system ponding. Method 5 is considered to be particularly advantageous in situations where inlet control devices (ICDs) are in place or may be considered as part of construction works. Although methods 3 and 4 assume that the catchbasin grate is the primary restrictor; in many cases (particularly with ICDs), it is, in fact, the catchbasin lead that is the restrictor. While method 3 could possibly be revised to represent the catchbasin lead rather than the grate, this revision would be a more onerous undertaking. Nevertheless, the modeling effort required is considered to be a disadvantage of method 5, given the requirement to implement an additional junction node representing the catchbasin structure, and to connect an additional orifice for the catchbasin lead. Automated tools in SWMM modeling software could potentially expedite this approach and make its implementation on larger models more practical.

\section{Summary and Future Work}

The assessments documented in this paper should assist modelers in determining an appropriate and defensible methodology to model inlets in SWMM. Based on the modeling results for these case studies and an overall assessment, it is considered that methods 4 and 5 (using orifices) are the most appropriate choices. Given the modeling effort currently associated with method 5, this approach may be limited to smaller study areas and to those where inlet control devices may be considered.

This study has been mainly concerned with the inlet modeling methodology in SWMM. The case studies used for this study and the results of the assessment of the methods could also be used to address more specific drainage system design questions and considerations that are related to catchbasins and inlets. It is proposed that a future study will accordingly continue the work advanced in this study. A number of design related items should be considered further, as outlined below.

The catchbasin grate type, in particular the performance of side inlet catchbasins (which are becoming increasingly common for roadway reconstructions in Ontario, especially where bicycle lanes are included) as compared to more standard bottom draw grates, warrants further consideration and attention. This could be addressed through modeling efforts in combination with available laboratory performance testing.

Catchbasin spacing for roadways also warrants further consideration. Currently, local municipalities and regulatory agencies 
specify minimum roadway inlet spacings based on the road classification (e.g. arterial, collector, local), the road profile grade, and other factors. The technical basis for these specifications is not well supported, however, and could be further assessed and confirmed through modeling.

Furthermore, the potential impacts of rainfall patterns modified by climate change could be assessed, to determine whether roadway standards should be modified to ensure that inlet capture systems are sufficiently resilient and will operate as intended.

Lastly, this assessment has focused primarily on the performance of roadway catchbasins and inlets. For residential developments, rear yard catchbasins (RYCBs) are a common feature, and in many cases are not fully accounted for, or modeled, as part of the overall drainage system design. A further modeling analysis of RYCBs would assist in better understanding performance considerations and potential effects on residential properties.

\section{Acknowledgments}

The authors gratefully acknowledge the following Ontario municipalities for allowing us to use the case study models for this paper: the City of Hamilton, the City of Welland, and the City of Guelph.

\section{References}

AMEC Environment \& Infrastructure. 2012. City of Guelph Stormwater Management Master Plan. Guelph: City of Guelph. https://guelph.ca/wp-content/uploads/StormwaterManagementMasterPlan.pdf

AMEC Environment \& Infrastructure. 2014. Hydrologic and Hydraulic Analysis of Storm Conveyance System, Binbrook and Shadyglen (Stoney Creek), City of Hamilton. Hamilton, Ontario: City of Hamilton. Report PED12182.

Bazin, P.-H., H. Nakagawa, K. Kawaike, A. Paquier and E. Mignot. 2014. "Modeling Flow Exchanges between a Street and an Underground Drainage Pipe during Urban Floods." Journal of Hydraulic Engineering 140(10). https://doi.org/10.1061/(ASCE)HY.1943-7900.0000917

Black, S. A. 1967. A Comparison of Catch Basin Inlet Grate Efficiencies. Toronto: Ontario Water Resources Commission. Division of Research Publication No. 18.

City of Welland. 2013. Municipal Standards. Welland, Ontario: Corporation of Welland.

https://www.welland.ca/Eng/pdfs/CityStandards.pdf

Despotovic, J., J. Pavsic, N. Stefanovic and D. Pavlovic. 2005. "Inefficiency of Storm Water Inlets as a Source of Urban Floods." Water Science and Technology 51 (2): 139-45.

GM BluePlan Engineering Limited. 2014. Pine Creek Estate Stormwater Peer Review. Welland, Ontario: Corporation of Welland.

James R., W. James and M. Lee. 2009. PCSWMM Urban Drainage Modeling Workbook (Version 3.31). Guelph: CHI Press.

Marsalek, J. 1982. Road and Bridge Deck Drainage Systems. Toronto: Ontario Ministry of Transportation Research and Development Branch. RR-228.

MTO (Ministry of Transportation Ontario). 1989. MTO Drainage Management Technical Guidelines. Toronto: Ministry of Transportation Ontario.

MTO (Ministry of Transportation Ontario). 1997. MTO Drainage Management Manual. Toronto: Ministry of Transportation Ontario.

http://www.ontla.on.ca/library/repository/ mon/12000/198363.pdf

OPS (Ontario Provincial Standards). 2016. Ontario Provincial Standards for Roads \& Public Works. Toronto: Queen's Printer for Ontario (Ministry of Transportation Ontario). http://www.raqsb.mto.gov.on.ca/techpubs/ops.nsf/OPSHomepage

Palla, A., M. Colli, A. Candela, G. T. Aronica and L. G. Lanza. 2016. "Pluvial Flooding in Urban Areas: The Role of Surface Drainage Efficiency." Journal of Flood Risk Management. https://doi.org/10.1111/jfr3.12246 